\title{
JERARQUÍA SOCIAL Y DESIGUALDAD ALIMENTARIA EN EL MEDITERRÁNEO NOROCCIDENTAL

\author{
EN LA BAJA EDAD MEDIA \\ LA COCINA Y LA MESA DE LOS \\ ESTAMENTOS POPULARES
}

\author{
ANTONIO RIERA MELIS \\ Universidad de Barcelona
}

\begin{abstract}
SUMARIO
1. Introducción.- II. Los sistemas alimentarios: 1. Los menestrales. 2. Los campesinos.- III. Conclusiones.
\end{abstract}

\section{INTRODUCCIÓN}

El mundo mediterráneo en la etapa final del Medioevo constitura un conglomerado de pueblos, un área donde coexistran y se interrelacionaban diversas culturas, la cristiana latina, la grecoortodoxa y la islámica. Resulta diff́cil, por lo tanto, intentar un análisis global de las diferentes cocinas que prosperaron entonces en las riberas del viejo Mare Nostrum' ${ }^{1}$. Para conjurar el peligro del descriptivismo pintoresco y superficial, he optado por circunscribir con rigor tanto el campo de observación, las tierras compredidas entre Niza y Alicante, como el objeto de estudio, los sistemas alimenta-

\footnotetext{
'Especialmente si se utiliza el término cocina en sentido amplio, si se considera que abarca, además del conjunto de los ingredientes y de las técnicas utilizadas en la preparación de la comida, "des représentations, des croyances et des practiques qui leur sont associées et qui sont partagées par les individus faisant partie d'une culture ou d'un groupe à l'intérieur de cette culture" (Cl. FISCHLER, L'Homnivore, Paris, Odile Jacob, 1993, p. 32).
}

"Anuario de Entudioe Medievales", 24 (1994) 
rios desarrollados por los menestrales urbanos y los campesinos. Me propongo, pues, reconstruir y comparar dos de los regímenes más estrechos y menos innovadores de cuantos crearon las ya complejas y estratificadas sociedades provenzal, occitana y catalana ${ }^{2}$, durante los siglos XIV y XV, una época en la que las diferencias, en el campo de la alimentación, dimanaban más, como ha recordado recientemente Stephen Mennell ${ }^{3}$, de la estructura social de cada país que de las fronteras políticas 0 lingürsticas.

Durante la segunda mitad del siglo XIII, se cierra en Occidente la etapa de colonización agraria que se inició hacia el 1050. En las riberas mediterráneas, todas las tierras cultivables con la tecnologia de la época ya estaban prácticamente en explotación. El incremento de la producción agraria, el establecimiento de unas nuevas relaciones de trabajo y el triunfo de una mentalidad más dinámica han enriquecido a los señores, han reactivado los intercambios entre la ciudad y el campo, han consolidado el mercado y la manufactura urbanos, y han multiplicado los circuitos del gran comercio internacional. El uso de la moneda y el crédito han dejado de ser

\footnotetext{
${ }^{2}$ En el seno de las formaciones sociales jerarquizadas, coexisten siempre diversas escalas de valores, diferentes visiones del mundo. Estas mentalidades dispares condicionan la actuación privada y pública de las personas, conforman las relaciones que establecen con los otros hombres y mujeres, con la naturaleza y con la divinidad, influyen en la manera como resuelven sus necesidades biológicas, afectivas e intelectuales. La religiosidad de un señor feudal es muy diferente a la de un campesino, como lo es también su sexualidad: espontánea y natalista entre los poderosos, para quienes un linaje amplio refuerza el poder, fuertemente controlada entre los payeses, que se ven obligados a adaptar, en la medida en que se lo permiten sus empíricos conocimientos fisiólogicos, la magnitud de la familia a la extensión del patrimonio. A cada estrato social le corresponde también un sistema alimentario específico, que le define como grupo. La alimentación, en cualquicr época, constituye un hecho cultural estrechamente relacionado tanto con el nivel material (biológico, económico, técnico) como con las estructuras mentales y el imaginario colectivo de cada estamento diferenciado [J.L. FLANDRIN, Historia de la alimentación. Por una ainpliación de perspectivas, "Manuscrits", 6 (Barcelona, 1987), p. 12; M. MONTANARI, Storia, alimentazione e storia dell'alimentazione. Le fonti scritte altomedievali, "Archeologia Medievale", VIII (Firenze, 1981), p. 36; A. RIERA MELIS, El sistema alimentario como elemento de diferenciación social en la Alta Edad Media. Occidente, siglos VIII-XII, "Representaciones de la sociedad en la Historia. De la autocomplacencia a la utopía", Valladolid, Instituto de Historia Simancas, 1991, pp. 10-11. IDEM, Alimentació $i$ poder a Catalunya al segle XII. Aproximació al comportament alimentari de la noblesa, "Revista d'Etnologia de Catalunya", 2 (Barcelona, 1993), p. 8.]. La reconstrucción de estos regímenes es tanto más precisa cuanto más alto es el grupo al que corresponde, puesto que la documentación conservada suele ser directamente proporcional al rango de su titular. Cuanto más poderoso y solvente es un colectivo, más documentación produce y mejor acostumbra a conservarla.
} y 70.

${ }^{3}$ Français et anglais d table, du moyen âge d nos jours, Paris, Flammarion, 1987, pp. 65 
unas prácticas exclusivamente burguesas, como se desprende de la alarma que la rápida difusión social del afán de lucro suscita entre los moralistas escolásticos.

La capacidad de crecimiento de las sociedades feudales no era, sin embargo, ilimitada. Después de más de doscientos años de expansión empiezan a emerger, hacia el 1280, las contradicciones internas del sistema. El equilibrio, siempre precario, entre población y recursos se está rompiendo. Este cambio de tendencia, sin embargo, no es imputable sólo a un dispar comportamiento de la demografía y de la oferta global de alimentos, obedece también a otras causas, como una estructura social fuertemente jerarquizada, que favorece la distribución desigual de los recursos entre los diversos estamentos, y una tecnología agraria débil, de evolución lenta y poco compatible con los planteamientos intensivos. De una época de relativa bonanza se pasa, en el curso de unas pocas décadas, a otra muy diferente, caracterizada por las dificultades intermitentes, por la alternancia de las crisis con las recuperaciones, más perceptibles en el sector primario que en el gran comercio o las finanzas.

Un conjunto de fenómenos heterogéneos pero estrechamente relacionados entre sí, como la subida lenta pero ininterrumpida de la población, el avance casi continuo de los frentes roturadores, el retroceso paralelo de los yermos, la instauración de una nuevas relaciones de producción, del orden feudal ${ }^{4}$, en el campo, la paulatina articulación de la economía agraria a los circuitos mercantiles interiores y el despegue -pausado- de los intercambios exteriores, habia dejado sentir, en la etapa central de la Edad Media, sus efectos sobre amplios sectores de las sociedades europeas. La "agrarización" de la economía rural, impulsada por los señores" y protago-

\footnotetext{
${ }^{4}$ Que había incrementando considerablemente, al disgregar las antiguas estructuras comunitarias rurales, de solidaridad horizontal, el control ceonómico y jurídico de los señores sobre los payeses.

SPara quienes el cultivo del trigo y de la vid, dos alimentos de notable calidad y de fácil almacenamiento, conservación y distribución, se revcló, en el contexto de una economía cada vez más abierta y monetaria, como la modalidad más rentable de explotación del suelo. Este cambio de planteamientos en la gestión de los señorios se tradujo, desde principios del siglo XII, en una multiplicación de las tenencias y en la generalización de los censos en cereales panificables y en vendimia. Los grandes propieturios estimularon, con inversiones considerables, el avance de las sementeras, pero procuraron trasladar, aprovechando la expansión demográfica, el grueso de la tarea roturadora sobre el excedente de mano de obra que periódicamente se acumulaba en sus múltiples inansos y sobre los numerosos hombres libres que, faltos de recursos, afluían hacia los señorios en demanda de ticrras en usufructo. De esta sinergia surgieron numerosos borghi, suavetés, basticles, puchlas y villas, que transformaron
} 
nizada por los payeses, las restricciones impuestas por los poderes locales a la libre explotación de los bosques, la multiplicación de los mercados rurales y la apertura de las fronteras a la oferta y la demanda exteriores ${ }^{6}$ tuvieron importantes consecuencias alimentarias, contribuyeron a acentuar las diferencias, ya importantes, que separaban las dietas de las aristocracias de las de los estamentos subalternos.

Los alimentos de origen vegetal habían avanzando, entre las capas bajas, a expensas de la carne, cuyo consumo había experimentado, excepto en los bien surtidos comedores de la nobleza, la alta clerecía y el patriciado urbano, un retroceso substancial' ${ }^{7}$. Las dietas de los estratos sociales inferiores han perdido, entre 1100 y 1280 , la variedad que las caracterizo durante el Alto Medievo ${ }^{8}$; los cereales han eclipsado las restantes viandas, relegándolas, como en la época romana ${ }^{9}$, a la condición de companage.

El pan se ha convertido, para amplios sectores de la sociedad, en el principal escudo contra el hambre y la enfermedad. Su ausencia constituye una privación poco menos que insoportable, puesto que doscientos años de crecimiento agrario han sumido en el olvido los comestibles alternativos como las castañas, las bellotas o las nueces. Fuentes de todo tipo atestiguan la revalorización de este alimento. El término "pan", durante los siglos XII y XIII, ha ampliado paulatinamente su ámbito semántico, llegando a incluir el trigo y los demás cereales panificables ${ }^{10}$; las sementeras han pasado a designarse, en los documentos italianos, terre panis y las mieses, recoltu

profundamente los paisajes agrarios en la Europa occidental.

${ }^{6}$ Mediante la concesión, por parte de las Administraciones central y locales, de facilidades de tráfico y exenciones arancelarias a los comerciantes nacionales y extranjeros.

${ }^{7}$ M. MONTANARI, Campagne inedievali. Strutture produltive, raporti di lavoro, sistemi alimentari,Torino, Einaudi, 1984, p. 209.

${ }^{8}$ Bien analizada por M. MONTANAR, L'alimentazione contadina nell'alto Medioevo, Napoli, Liguori, 1979, pp. 429-431.

${ }^{9} \mathrm{M}$. Montanar, Alimentazione e cultura nel Medioevo, Bari, Laterza, 1988, pp. 13-21.

${ }^{10} \mathrm{La}$ comunidad cisterciense de La Real, en abril de 1248, cede en enfiteusis una tercera parte de la villa de Deià (Mallorca) a Pere Ramon Porter, con la condición de que éste le entregue anualmente, en concepto de censo, "quartum et decimam de vindemia...et de olivis et de exitibus partis tue molendinorum..., et de ommni fructu panis, canabi et lini, octavam partem et decimam" (P. MORA-L. ANDRINAL, Diplomatari del monestir de Santa Maria de La Real de Mallorca, I, Palına de Mallorca, 1982, doc. 44, p. 262). 
panis $^{11}$; ejemplos parecidos abundan en los contratos agrarios pronvenzales y catalanes coetáneos.

Las ciudades, hacia 1280, continúan aprovisionándose de cereales en las campiñas circundantes y en los mercados rurales situados dentro de sus respectivas áreas de influencia, cuya extensión depende básicamente de la magnitud del núcleo a abastecer ${ }^{12}$. Cuando la demanda supera ampliamente a la oferta regional, los comerciantes también aportan grano, en contingentes exiguos y con unos costos de transporte considerables ${ }^{13}$, desde zonas lejanas. La posibilidad de una escasez de pan empieza a obsesionar a las capas medias y bajas urbanas, que, al considerar a la agricultura como el princial valladar frente a la penuria ${ }^{14}$, contemplan con recelo la paralización de las roturaciones y defienden el avance de la cerealicultura, la conveniencia de reducere terram ad panem ${ }^{15}$, en el hinterland de las ciudades. El comercio puede atenuar una carestía pero no constituye todavía, por la lentitud y limitada capacidad de carga de los medios de transporte, la embarcación y la recua, una defensa eficaz ante una crisis de subsistencia generalizada. La agricultura mediterránea es, sin embargo, de una calidad mediocre, que la diversidad de condiciones locales y las importaciones contribuyen a disimular. El protagonismo de la pequeña explotación payesa en la producción de cereales ${ }^{16}$ dificulta, por otra parte, la renovación tec-

\footnotetext{
${ }^{11}$ M. MontanaR, Campagne medievali, pp 157 y 201.

${ }^{12} \mathrm{G}$. Duby, hacia 1960, calculó que, en pleno siglo XIII, para cubrir la demanda cerealista de una pequeña aglomeración de 3000 habitantes, se necesitaba, en Francia, en los años normales, un área roturada del orden de las 3000 ha. (cit. G. FOURQUIN, Histoire Econornique de l'Occident Médiéval, Paris, Armand Colin, 1969, p. 209). En las riberas mediterráneas, más secas y con unos suelos menos potentes que las llanuras atlánticas galas, se precisaría una superficie algo más extensa, no inferior a las 4000 ha.

${ }^{13}$ Por lo menos hasta la difusión, en el último tercio del siglo XIV, de los fletes diferenciados, cuyo precio no dependía sólo del volumen o peso del cargamento y de la distancia a recorrer, como en los antiguos, sino también del valor de las mercancías que lo integraban. Su positiva incidencia en el gran comercio internacional ha sido analizada detenidamente por Federigo MELJS, Werner Sombart e i problemi della navigazione nel Medioevo, "I trasporti e le comunicazioni nel Medioevo", Prato, Istituto Intemazionale di Storia Economica "Francesco Datini", 1984, pp. 36-68.

14 "Radulfus ergo, videns et sciens ecclesiam pauperum redditibus carentem sine agricoltura non facile posse subsistere, totum studium suum ad emendas et adquirendas terras convertit" (pasaje del Liber de Restauracione Sancti Martini Tomacensis, citado por M. MONTANAR, $L$ 'alimentazione contadina, p. 438, nota 48).

${ }^{15}$ M. MONTANAR, Campagne medievali, pp. 202-203

${ }^{16}$ Puesto de manifiesto por G. BoIS, La crisi del feudalisme a Europa a la fi de l'Edat Mitjana, Barcelona, Societat Catalana d'Estudis Histórics, 1986, pp. 23-25
} 
nológica en el campo. La debilidad crónica de los rendimientos, más que las oscilaciones climáticas, complica a menudo la "soldadura". La expansión de las ciudades y los cambios en la dieta ordinaria de amplios sectores de la población urbana, al romper paulatinamente los antiguos equilibrios regionales, acentúan, desde 1300, la dependencia del mercado local de alimentos del gran comercio internacional. Barcelona, Valencia y Mallorca, como Génova o Venecia, empiezan a consumir, además de los cereales producidos dentro de las fronteras de sus respectivos estados, blat de mar, trigo importado de Sicilia, Provenza, el Magreb y Castilla ${ }^{17}$. Los concejos de estas grandes urbes, conscientes de esta dependencia exterior, improvisan una serie de medidas tendentes a estimular la afluencia de cereales ${ }^{18}$, a contener los peligrosos efectos de las bruscas cafdas de la oferta interior. Cuando esta tarea de los ediles se revela infructuosa, sólo cabe esperar el arribo fortuito de víveres, que los estamentos populares -alarmados- suelen atribuir más a la intervención divina que al afán de lucro de los mercaderes: desde mediados del siglo XIV, la hagiografía recoge un nuevo tipo de milagro, la llegada providencial, a una ciudad hambrienta, de una nave foránea cargada de grano ${ }^{19}$. Paradojicamente es entre la población rural, menos organizada políticamente que la urbana, donde los efectos de las

\footnotetext{
${ }^{17} \mathrm{Cl}$. CARR广KKE, Barcelona 1380-1462. Un centre econòmic en època de crisi, I, Barcelona, Curial, 1967, pp. 339-366. L. STOUFF, Ravitaillement et alimentation en Provence aux XIVe et XVe siècles, Paris-La Haye, Mouton \& Cie., 1970, pp. 58-82.

${ }^{18}$ Que iban desde el veluin bladi, la prohibición de la saca, hasta la compra directa de partidas de grano, por agentes del concejo, en los mercados extranjeros, pasando por la subvención de las importaciones. Esta política activa e intervencionista de los municipios en el abastecimiento frumentario de las ciudades ha sido estudiada, entre otros, por Cl. CARRERE, Barcelona 1380-1462, I, pp. 339-366; S. RIERA VIADER, El provelinent de cereals a la ciutat de Barcelona durant el "mal any primer" (1333): la intervenció del Consell de cent i de la Corona, "Il Congrés d'Història del Pla de Barcelona", 1, Barcelona, 1989, pp. 315-326; A. CURTO, La intervenció imunicipal en l'abastament de blat d'una ciutat catalana: Tortosa al segle XIV, Barcelona, Fundació Salvador Vives Casajuana, 1988; E. SERRA, Els cereals a la Barcelona del segle XIV, "Alimentació y societat a la Catalunya Medieval", Barcelona, Consejo Superior de Investigaciones Científicas, 1988, pp. 71-107; P. TUTUSAUS, Un mal any en la ciutat de Barcelona (1374-1375), Tesis de Licenciatura, Universidad de Barcelona, 1986, dactilografiada; P. ORT1, El forment a la Barcelona baixmedieval: preus, mesures $i$ fiscalitat (1283-1345), "Anuario de Estudios Medievales", 22 (Barcelona, 1992), pp. 377-423; M. TANgheroni, Aspetti del comınercio dei cerali nei Paesi della Corona d'Aragona. 1. La Sardegna, Cagliari, Consiglio Nazionale delle Ricerche, 1981, pp. 75-78; y L. STOUFF, Ravitaillement et alimentation en Provence, pp. 72-79]

${ }^{19}$ Una pequeña tabla de Pietro di Giovanni d'Ambrogio, "La llegada milagrosa del grano", pintada hacia 1435 y que se conserva actualmente en Dahlem-Museum de Berlín, constituye un bello y claro ejemplo iconografico de esta nueva modalidad de asistencia divina a las poblaciones desabastecidas pero devotas.
} 
crisis de subsitencia se dejan sentir con más intensidad. Los pequeños propietarios y los colonos, una vez agotadas sus reservas alimentarias y las de las modestas almoines parroquiales inmediatas, se ponen en movimiento y acuden, en busca de víveres, a los monasterios y a las ciudades abastecidas con grano de importación ${ }^{20}$.

Las escaseces frumentarias, poco frecuentes durante la etapa central de la Edad Media, se repiten, desde el último tercio del siglo XIII, a un ritmo cada vez más rápido, provocando periódicas situaciones de emergen$\mathrm{cia}^{21}$. En Catalunya, las crisis de subsitencia bajomedievales se incian en 1333, con el mal any primer, cuyas secuelas aparecen descritas con inusitado detalle en la cronística coetánea. Unos años más tarde, en 1348, se abate sobre la población europea un segundo flagelo, la peste, provocando unas fuertes pérdidas demográficas y una súbita contracción del área cultivada. Los rebrotes de la epidemia, las malas cosechas y las plagas retrasarán el restablecimiento de la normalidad. Las intermitentes carestras frumentarias, el auge de la ganadería y el incremento subsiguiente de la oferta de carne y de queso constituirán algunos de los efectos más visibles de reavance de los yermos, imputable tanto a rigidez de las estructuras agrarias como a la falta de fuerza de trabajo.

Las retireadas crisis cerealistas comprometen, desde mediados del siglo XIV, el normal abastecimiento de las ciudades del Mediterráneo noroccidental y obligan a los concejos a mirar más allá de las regiones circundantes, a fin de buscar provisiones en territorios cada vez más leja-

\footnotetext{
${ }^{20} \mathrm{El}$ hambre, en 1256, alcanza tal intensidad en el contado de Lucea que muchas familias campesinas, para poder sobrevivir, abandonan sus explotaciones y acuden a Bolonia, en busca de asistencia (A. RIERA MEIJs, Els pròdroms de les crisis agràries de la Baixa Edat Mitjana a la Corona d'Aragó. 1: 1250-1300, "Miscel.lània en homenatge al P. Agustí Altisent", Tarragona, Diputació Provincial, 1991, p. 41). La falta de alimentos provoca, en 1276, migraciones rurales en Lombardía, Liguria y Toseana, los labradores se dirigen hacia las grandes ciudades, atraídos por las reservas fruınentarias alınacenudas en los graneros municipales (bidem, p. 44). La amentzadora presencia de inasas campesinas hanbrientas en las puertas de las grandes plazas mercantiles se repetirá periódicamente, durante los siglos XIV y $\mathrm{XV}$, en todos los países cristianos de la cuenca occidental del Mediterráneo.
}

${ }^{21}$ S. AgUADE, En los origenes de una coyuntura depresiva. La crisis agraria de 1255 a 1262 en la Corona de Castilla. "De la sociedad areaica a la socicdad campesina en la Asturias medieval", Madrid, Universidad de Alcalá de Henares, 1988, pp. 333-370; La crisis de la segunda mitad del siglo XII en Asturias, "Ihidem", pp.371-390. A. RIERA MEIJS, Els prddroms de les crisis agràries, pp. 35-72. R.S. GoTIFRILD, La Muerte Negra. Desastres en la Europa medieval, México, Fondo de Cultura Económica, 1989, pp. 67-82. E. CARPENTIER, Autour de la peste noire. Famines et épidernies dans l'histoire du XIV siècle, "Annales. Economies. Sociétés. Civilisations", XVII (Paris, 1962), pp. 1062-1092. 
nos, en Cerdeña, Nápoles, la costa dálmata, Portugal, Flandes, Normandía y Borgoña ${ }^{22}$. El comercio internacional, hasta 1300 , había puesto en circulación preferentemente artículos de lujo, de alto valor y escaso peso, destinados a los estamentos privilegiados. Además de los tejidos de calidad, las especias, el oro, las armas, los esclavos, las pieles finas, la lana inglesa o la grana, sólo efectuaban largos recorridos mercantiles los alimentos imprescindibles, como el trigo, la sal y el vino. La acentuación de la divisón social del trabajo, el incremento de la productividad de los medios de transporte, especialmente de los marítimos, y la difusión de unas técnicas mercantiles, contables y financieras más decididamente capitalistas permiten, durante el segundo tercio del centuria, la incorporación progresiva a los circuitos del gran comercio internacional de los productos pobres y de los comestibles no vitales, cuyas transacciones se incrementan ininterrumpidamente en los mercados urbanos y rurales. El trático creciente de alimentos ordinarios permite una cierta especialización regional y amplía considerablemente el segmento social que depende, para su abastecimiento cotidiano, del mercado. La aristocracia y el patriciado urbano, con un poder adquisitivo elevado, difícilmente desestabilizable por las oscilaciones de coyuntura, serán los grandes beneficiarios de esta alza de la oferta mercantil de alimentos, que les permitirá diversificar aún más su ya extensa dieta ordinaria.

Las dificultades económicas y los cambios estructurales actúan sobre el conjunto social de forma selectiva, acentuando su jerarquización interna. Los alimentos -bienes limitados e imprescindibles- se distribuían, durante la Baja Edad Media, de forma muy desigual entre los diversos estamentos. Mientras los pobres sólo tenían acceso a una estrecha gama de manjares y pasaban hambre incluso en los años de buena cosecha, los poderosos aprovechaban las nuevas circunstancias para renovar su dieta y atravesaban las crisis de subsistencia sin restringir apenas su régimen alimentario. La penuria y el derroche, el miedo a morir de inanición y el afán por elevar el techo gastronómico, coexistían permanentemente, constitufan, según Massimo Montanari ${ }^{23}$, dos realidades indisociables.

\footnotetext{
${ }^{22}$ E. SERRA, Els cereals a Barcelona, pp. 72-78.

${ }^{23} \mathrm{El} \mathrm{hambre} \mathrm{y} \mathrm{la} \mathrm{abundancia.} \mathrm{Historia} \mathrm{y} \mathrm{cultura} \mathrm{de} \mathrm{la} \mathrm{alimentación} \mathrm{en} \mathrm{Europa,} \mathrm{Barcelona,}$ C.rítica, 1993, p. 98.
} 


\section{LOS SISTEMAS ALIMENTARIOS}

Cada estamento social, como ya se ha expuesto, desarrollo, entre 1280 y 1500 , su propio sistema alimentario, selecciono, de acuerdo con sus posibilidades respectivas, una gama más o menos amplia de viveres, les atribuyó, según un criterio no estrictamente funcional ${ }^{24}$, un valor determinado y los combinó de forma diferente. El resultado consistió en una serie de regímenes muy diversos. El proverbio catalán "el ric menja quan vol, cl pobre quan pot i el monjo quan li toca" es aplicable también a las sociedades pretéritas del Mediterráneo noroccidental.

\section{Los menestrales y el "poble menut", la sobriedad forzosa como} norma

Por debajo de la poderosa y culta alta burguesía existía, en las ciudades bajomedievales, una amplia franja de población, la terça $m d$, integrada fundamentalmente por menestrales ${ }^{25}$, con un poder adquisitivo y una influencia política muy inferiores. La documentación sobre la vida privada, a medida que vamos descendiendo en la escala social, se hace más escasa e inexpresiva. Tanto para el artesano que trabajaba en su obrador como para el asalariado que lo hacla por cuenta ajena, comer cada día constituirra una preocupación constante. La escasa cuant $\mathfrak{a}^{26}$ y la irregularidad de sus ingresos les colocaba en una situación difícil frente a las oscilaciones de precios de los alimentos, puesto que, al no disponer de propiedades rurales, dependian, para su abastecimiento diario, del mercado local.

\footnotetext{
${ }^{24}$ Puesto que el lugar que ocupa cada vianda en la escala de preferencias no depende sólo de su poder nutritivo ni de su abundancia o escasez relativas. "La escala de valores gastronómicos de un pueblo, de una región, de una clase social o de un individuo dependen tanto de un conjunto de razones socioculturales como de razones naturales y económicas" (J.L. FLANDRIN, Historia de la alimentación, p. 12).

${ }^{25}$ "La terça mà s'apella de menestrals, així com són argenters, ferrers, sabaters, cuiracers, e així dels altres" (F. EIXIMENIS, La societat catalana al segle XJV, ed. J. Webster, Barcelona, Edicions 62, 1980, p. 12).

${ }^{26}$ Del orden de los 20 florines anuales, durante el último cuarto del siglo XIV, según Francesc Eiximenis (T.M. VINYOLES, El pressupost faniliar d'una mestressa de casa barcelonina per l'any 1401, "La societat barcelonina a la Baixa Edat Mitjana", Annex a "Acta Historica et Archacologica Mediacvalia", Barcelona, 1983, pp. 108-109).
} 
La dieta ordinaria de los estamentos populares urbanos se apoyaba sobre el pan de trigo ${ }^{27}$, por lo menos en las épocas normales, a cuya adquisición consignaban casi la mitad de su presupuesto alimentario. Incialmente la mayoría de las familias menestrales preparaban las hogazas en casa $^{28}$ y las cocían fuera, en el horno del barrio, cuyo concesionario se quedaba, en pago por su trabajo, una parte de la hornada, normalmente $1 / 20$, que destinaba a la venta. Desde 1350 aproximadamente, se difunde, sin embargo, la costumbre de encargar la fabricación del pan cotidiano a un panadero, a quien se entrega periódicamente partidas de cereales, o de adquirir el pan $^{29}$ en una fleca de ros, tahona especializada en la manipulación de harinas integrales de trigo, más baratas que las refinadas ${ }^{30}$. Este cambio de usos, que parece obedecer a un afán por consumir pan de mayor calidad, más reciente y menos duro, estimula a los poderes locales a construir nuevos hornos ${ }^{31}$ y consolida el ascenso económico y social de los panaderos, que se convierten, como los carniceros, en un colectivo solvente. La mejora de las expectativas profesionales provoca un desplazamiento casi sistemático de las mujeres, al frente de las tahonas, por los hombres. La fabricación de pan para la venta, que empezó como una actividad femenina, se transforma, en la segunda mitad del siglo XIV, en una digna y rentable tarea masculina ${ }^{32}$.

Durante las frecuentes crisis frumentarias, las autoridades municipales repercutían la restricción de la oferta de cereales en el peso y la

\footnotetext{
${ }^{27}$ J.V. GARCIA MANSILIA, La jerarquía de la mesa. Los sistemas alimentarios en la Valencia bajomedieval, Valencia, Dipulación Provincial, 1993, p. 259. A. CURTO, La intervenció municipal en l'abastanent del blat, pp.35-36. E. SERRA, Els cereals a la Barcelona del segle XIV, pp. 71-79. L. STOUHF, Ravitailleinent el alimentation en Provence, pp. 47-50. M. MONTANARI, Campagne medievali, p. 203.

${ }^{28}$ Como se desprende de la presencia, en bastantes inventarios, de "unam tabulam ad portandu m panum ad furmum" (L. STOUFF, Ravitaillement et alimentation en Provence, p. 31).

${ }^{29} \mathrm{~L}$. STOUFF, Ravitaillement et alimentation en Provence, pp. 37-38.

${ }^{30} \mathrm{~L}$. STOUFF, Ravitaillement et alimentation en Provence, pp. 48-49. J.V. GARCIA MANSILLA, La jerarquía de la inesa, pp. 110-111.

${ }^{31}$ En Barcelona -según Pere Ortí, a quien agradezco la información, todavía inéditafuncionaban, a finales del siglo XIV, 54 panaderias. Por esta misma época, la ciudad de Valencia disponía de 87 homos (J.V. GARCla MARSILA, La jerarquia de la mesa, pp. 111118). Los vecinos de la capital balear, en 1478, podían adquirir, cada día, pan reciente o cocer sus hogazas en 29 tahonas (M. BARCELO, Ciutat de Mallorca en el Trànsit a la Modernitat, Palma de Mallorea, Institut d'Estudis Baleàrics, 1988, p. 166).

${ }^{32}$ Entre los contribuyentes de la Ciutat de Mallorca figuran, en 1483, 31 flaquers y 1 flaquera (M. BARCELO, Ciutal de Mallorca, p. 170).
} 
composición del pan, no en el precio, que procuraban mantener inaltera$\mathrm{do}^{33}$, limitaban la cuantía del hornaje, colocándola por debajo de 1/25 de las unidades cocidas $^{34}$, y adoptaban una serie de medidas tendentes a incrementar la oferta de cereales ${ }^{35}$. El concejo, consciente del importante papel que este producto jugaba en el régimen alimentario de amplios sectores de la población urbana, ejerció siempre un control estrecho sobre el comercio de granos $^{36}$ y sobre el funcionamiento de los hornos y de las tahonas de la ciudad ${ }^{37}$, a fin de garantizar a las capas subalternas un abastecimiento fluido de pan, amortiguando las oscilaciones de precio y de calidad.

La ración diaria de pan oscilaria, en función del precio del trigo, entre los 400 y los 700 gramos por persona. El pan se habla convertido en un alimento tan esencial que, antes de de 1200 , se le atribuyó un fuerte simbolismo religioso. Cuando, a mediados del siglo XII, se generalizan, entre todos los estamentos de la sociedad, las misas de difuntos, se impone

\footnotetext{
${ }^{33}$ La medida -de carácter antiinflacionista- de hacer depedender del precio del trigo el peso del pan y no su valor, que ya se aplicaba en Constantinopla a fines del siglo IX (A.I. PINI, Cittd, comuni e corporazioni nel medioevo italiano, Bologna, CLUEB, 1986, pp. 233-234), estará en vigor, durante toda la Baja Edad Media, en las ciudades catalanas, como lo demuestran los casos de Perpiñán (Archives Communales de Perpignan, Livre Vert Mineur, fols. 8586; ed. B.J. ALART, Documents sur la langue catalane des anciens comtés de Roussillon et Cerdagne, Paris, Maisonneuve et Cie., 1881, pp. 230-231) y de Balaguer (Arxiu Històric Comarcal de Balaguer, Llibre de Bans i Ordinacions, fols. 58 r.-59 v.), y provenzales (L. STOUFF, Ravitaillement et alimentation en Provence, p 32).

${ }^{34} \mathrm{~L}$ STOUFF, Ravitaillement et alimentation en Provence, p. 32.

${ }^{35}$ Véase supra, p. 862, nota 18.

${ }^{36}$ Ibidem.

${ }^{37} \mathrm{La}$ inspección de las panaderías, en Perpiñán, corría a cargo, desde 1275 , de dos prohombres, seleccionados por el batlle y los cónsules municipales, no por los propios panaderos (Archives Communales de Perpignan, BB 7, fol. 1 r.; regest. B.J. ALART, Docuinents sur la langue catalane, p. 66). En Barcelona, antes de 1284, ya había unos pesadores del pan, elegidos anualmente por el batlle y el concejo, puesto que Pedro el Grande, en el Recognoverunt proceres, confirma el cargo y su mecanismo de renovación: "Item capitulum quod ponderatores panis remutentur de anno in annum, cuin voluntate baiuli et proborum hominum, et quod non sint perpetuales concedimus, eo modo ut in vestro privilegio continetur" (Archivo de la Corona de Aragón, Cancillería, Ciudad de Barcelona, pergamino original; ed. A.M. ARAGO-M. CosTA, Privilegios reales concedidos a la ciudad de Barcelona, "Colección de documentos inéditos del Archivo de la Corona de Aragón", XLIII, Barcelona, 1971, doc. 22, p. 16. La supervisión de la calidad del pan, en las ciudades provenzales, había sido confiada también, por esta misma época, a unos ponderatores panis, designados por las autoridades locales (L. STOUFF, Ravitaillement et alimentation en Provence, p. 33).
} 
la costumbre de entregar, en el ofertorio, un pan de un dinero, usanza que continuaba vigente en Barcelona hacia 1400.

El consumo de carne fresca, entre la pequeña burguesía, retrocedió sustancialmente, en cambio, entre 1100 y $1350^{38}$, a pesar de las medidas adoptadas por los ediles para evitar las bruscas oscilaciones de $\operatorname{precios}^{39}$ y garantizar su salubridad ${ }^{40}$. Los menestrales, incluso después del auge experimentado, a ráz de la Peste Negra, por la ganadería, sólo tenían acceso a las variedades menos selectas y más baratas: la cabra, la oveja ${ }^{41}$, el macho cabrío y la cerda ${ }^{42}$. El carnero ${ }^{43}$ se reservaba para los escasos ágapes extraordinarios, festivos o funerarios ${ }^{44}$. La exigua presencia de carne fresca en la dieta cotidiana ${ }^{45}$ poducía frustración entre las familias menos solventes, que la consideraban, como los restantes estamentos sociales, el mejor sustento para el hombre, una vianda que ayudaba a conservar la salud y a superar la enfermedad. Su carencia era compensada parcialmente con tocino salado y algunas legumbres y verduras de poco valor. El potaje

\footnotetext{
38 "La viande n'est pas, pour la plupart des homes de ces temps, un aliment quotidien; pour beaucoup, sa consomation se limite aux dimanches et aux jours de fêtes. C'est a dire aussi que tout Provençal, même citadin, même Carpentrassien, n'est pas forcement bien nourri, ni gros mangeur de viande" (L. STOUFF, Ravitaillement et alimentation en Provence, p. 194). En Cataluña, la situación no debió de ser muy diferente. En las ciudades de la Italia septentrional, los estratos subaltemos urbanos, según el cronista Ricobaldo de Ferrara, sólo comían came fresca tres veces a la semana: "plebeii homines ter in septimana camibus recentibus vescebantur. Tunc pradio edebant olera cocta camibus. Coenam autem ducebant ipsis camibus frigidis reservatis" (L.A. MURATORI, Antiquitates Italicae Medii Aevii, II, Milano, 1739, col. 310).

${ }^{39}$ Cuya cuantía máxima, en Provenza, era revisada tres veces al año: por Pascua, San Juan y Navidad (L. STOUFF, Ravitaillement et alimentation en Provence, p. 135).

${ }^{40}$ Concentrando las transacciones de came de calidad en las camicerias, prohibiendo la venta en ellas de came procedente de animales accidentados, enfermos o sacrificados fuera de la ciudad, limitando a 2 o 3 días el período legal de venta de la came fresca y restrigiendo la oferta de cames cocidas. El rigor de estas nonnas no debe sobrevalorarse, puesto que, fuera de las camicerías, regía un "liberalismo" casi absoluto.

${ }^{41}$ Cuyos precios oficiales, en Barcelona, no superaban, durante el bienio 1232-1233, los 9 dineros la libra (J. MUTGE, L'abastament del peix $i$ de la cam a Barcelona, en el primer ters del segle XIV, "Alimentació i societat a la Catalunya Medieval", pp. 118-119).

${ }^{42} \mathrm{~L}$. STOUFF, Ravitaillement et alimentation en Provence, p. 135.

${ }^{43}$ Cuya cotización oficial, en la capital catalana, no bajó nunca, durante el bienio 1332 1333, de los 11 dineros la libra (J. MUTGE, L'abastainent del peix $i$ de la carn, p. 264).

${ }^{4} E Q U I P$ BROIDA, Els dpats funeraris segons els testaments vers 1400, "Alimentació i societat a la Catalunya medieval", p. 267.

${ }^{4}$ Especialmente en primavera, cuando las dificultades de aprovisionamiento provocaban, por lo menos en Provenza, una considerable elevación de precios (L. STOUFF, Ravitaillement et alimentation en Provence, pp. 135 y 181-186).
} 
de habas, lentejas o guisantes, la menestra de col y cebolla, y el caldo de carne salada con sopas de pan duro debran de aparecer a menudo en las mesas humildes. La calabaza, en verano, y las espinacas y los puerros, en invierno, aportarían un poco de fantasía a este régimen monótono. La fruta, considerada como un alimento superfluo, como un lujo reservado a las clases altas, ocupo, en cambio, un lugar periférico en al dieta ordinaria del poble menut.

El vino corriente de la tierra enriquecía en hidratos de carbono una dieta deficitaria en lípidos y proténas. El consumo diario por persona se situaría por debajo de los tres cuartos de litro, nivel propio de los miembros de la alta burguesía ${ }^{46}$. La penuria de vino se revela, en las grandes ciudades, como más soportable que la de pan. En los años de mala vendimia, el consistorio se limita a liberalizar las importaciones y no pone en funcionamiento ningún otro de los mecanismos ideados para superar las crisis cerealistas. La escasez de vino sólo inquieta a los reponsables municipales durante las epidemias o cuando la calidad del agua suscita recelos entre amplios sectores de la población. El concejo de Barjols, en octubre de 1403, busca vino en el exterior, para atender las necesidades de los numerosos vecinos enfermos, interesante testimonio de las virtudes curativas atribuidas, a finales de la Edad Media, al mosto fermentado en Proven$\mathrm{za}^{47}$. Los médicos catalanes, en cambio, no incluyen el vino entre los posibles remedios de la peste, desaconsejan el consumo, durante las epidemias, de los caldos fuertes y dulces ${ }^{48}$, recomiendan reducir sensiblemente las raciones y sugieren concentrar su ingestión al final de las comidas ${ }^{49}$. Con vino blanco y una amplia gama de componentes vegetales, la farmacología mediterránea bajomedieval, continuando una tradición heredada de los árabes, preparaba un conjunto de bebidas medicinales, para remedio de numerosas enfermedadades, como la depresión, la amnesia, la ictericia, el

${ }^{46}$ T.M. VINYOLES, El pressupost familiar, p, 108.

${ }^{47} \mathrm{~L}$. STOUFF, Ravitaillement et alimentation en Provence, p. 88.

${ }^{48} \mathrm{~J}$. VENY, "Regimen de preservació de pestilencia" de Jacine d'Agramont (s. XIV), Tarragona, Diputació Provincial, 1971, p. 81.

${ }^{49} \mathrm{Ll}$. ALCANY1s, Regionent preservatiu $i$ curatiu de la pestilencia, Valencia, N. Espindeler impr., s. a., fol. Vr. y Vv.; cit. J.V. GARCla MARSILL, La jerarquia de la inesa, p. 90. 
asma, las ventosidades o el restreñimiento ${ }^{50}$. La incidencia de estas recomendaciones en las prácticas alimentarias de los estamentos populares, para quienes la medicina universitaria constitura un lujo inalcanzable, debio de ser, sin embargo, escasa.

En los días de vigilia, un trozo de queso, de arenque o congrio salados, o un huevo constituirian el companage normal. El pescado fresco, con una oferta bastante más baja, incluso en la ciudades marítimas, que la de la carne, se vendía, excepto el delfín, el atún, la sardina y la corvina, a unos precios ${ }^{\mathrm{sl}}$ poco asequibles para la menestralía. Las autoridades municipales, conscientes de este problema, procuraban asegurar el abastecimiento, atenuar las oscilaciones de precios y erradicar los fraudes. El control concejil era especialmente intenso durante la Cuaresma, cuando la demanda alcanzaba sus cotas máximas. En las poblaciones interiores, durante el verano, el pescado de mar, por razones higiénicas, sólo se vendía salado. La pesca, incluso la recién capturada en los mares cercanos, la más sabrosa, suscitaba escaso entusiasmo entre amplios sectores de la sociedad, que, al considerarla como una vianda de calidad inferior a la de la carne, poco atractiva, más apta para la mortificación que para el deleite, circunscribran su consumo a las jornadas penitenciales ${ }^{52}$. La presencia periodica del pescado en las mesas populares obedecía más a una imposición eclesiástica que a una opción de los comensales, de ahr que las familias artesanas no le asignaran un lugar importante en su presupuesto alimentario y prefirieran reservar los escasos recursos disponibles para la compra de otros manjares más suculentos y apetecibles.

La dieta podía llegar a ser, en las capas más bajas, muy estrecha y poco variada; un sector de la población urbana tendría que conformarse con unas rebanadas de pan negro de cebada, cebollas, ajos y, eventualmente, un

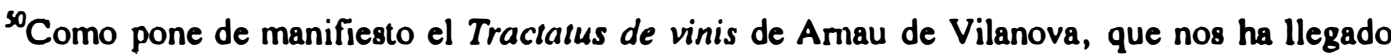
en diversos incunables, analizados brevemente por A.M. CARMONA y A. ESCUDERO en $E l$ vi en els incunables: "Tractatus de vinis", "Vinyes i vins: mil anys d'historia", Barcelona, Publicacions de la Universitat de Barcelona, 1993, I, pp. 377-379.

s'Superiores, en 1332-1333, a 3 dineros por libra, en Barcelona (J. MUTGÉ, L'abastament del peix i de la cam a Barcelona, p. 112).

\$2" La consommation de poisson aparaît précisément limitée dans le temps par des facteurs d'ordre religieux" (L. STOUFF, Ravitaillement et alimentation en Provence, p. 201).
} 
pequeño trozo de tocino, acompañados de agua o de vinagre ${ }^{53}$, régimen con un contenido calórico inferior al que ofrecian, durante la primera mitad del siglo XIV, las instituciones caritativas a algunos pobres locales. Para quienes vivir no era más que subsistir, la dieta que Francesc Eiximenis proponía como normal entre las familias de la pequeña burguesía, un plato de carne o de pescado, para almorzar, y otro de pescado o huevos, para cenar $^{54}$, constituirfa un anhelo poco menos que inalcanzable. La obligada sobriedad que presidra los hogares populares explica que sus moradores considerasen -como los campesinos coetáneos- la abundancia y diversidad de alimentos como la antesala de la felicidad ${ }^{\text {ss }}$.

\section{Los campesinos, entre la autosuficiencia alimentaria y el mercado}

La reconstrucción y el análisis de los sistemas alimentarios rurales, aunque las sociedades mediterráneas bajomedievales continuaron siendo eminentemente agrarias, constituyen para el historiador dos problemas complicados. La documentación que nos ha llegado se hace menos variada y expresiva a medida que nos alejamos de la ciudad. No disponemos, para reahacer las dietas, de fuentes directas y la información aportada por la arqueologia, muy puntual y dispersa, no ha dado origen todavía a síntesis interpretativas bien elaboradas. La población rural, por otra parte, no era, en la etapa final de Medioevo, un estamento uniforme sino fuertemente jerarquizado: el régimen de los payeses grassos, acomodados, con tierras suficientes como para subestablecer parte de ellas a familias pobres, a cambio de censo y derecho de entrada, cuyos ingresos ordinarios les permitran frecuentar los mercados cercanos, debfa de ser bastante más abundante y variada que la de los campesinos menuts, faltos de recursos, a quienes unos patrimonios reducidos y unas exigencias señoriales fuertes obligaban,

\footnotetext{
53"Que tomets a aquelles [viandes] en què fos nodrit, ço és, a pa d'ordi e a mengar cebes e aylls, e a vegades un poch de camsaluda, e que beguals de la aygua, axí com lavors reyets, o del vinagre bé amarat" recomicnda, hacia 1390. Francesc Eiximenis a un clérigo urbano de baja extracción social y escasa continencia (Com usar bé de beure e menjar. Normes inorals contigudes en el "Terç del Crestià", ed. J.J.E. Gravia, Barcelona, Curial, 1983, p. 46).

s4"En vida comuna, cascú és content de menjar, a dinar, cuyna ab cam o ab peix, [e, a sopar, peix] o ous o qualque cosa altra simpla en valor" (Coin usar bé de beure e menjar, p. 89).

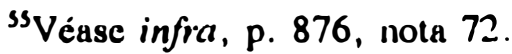


para poder sobrevivir, a ofrecer su trabajo, durante las mieses y los demás períodos de faenas estacionales, a los grandes y medianos propietarios. Para estas capas bajas de la sociedad rural, con una escasa capacidad de ahorrro, la autosuficiencia alimentaria constituiría aún el modelo más atractivo $^{56}$. Muchas familias se esforzarían por extraer de sus tierras los alimentos que necesitaban y sólo adquirirían, en los mercados, aquellos que no eran capaces de producir directamente, opción que, al no estimular los cambios, conferiría una estabilidad especial a su dieta ordinaria. Marc Bloch ya puso de manifiesto que los regímenes alimentarios, entre los siglos XI y XVIII, evolucionaron a un ritmo mucho más lento en el campo que en la ciudad ${ }^{57}$.

El contacto directo con los medios de producción y el papel marginal asignado al mercado en su abastecimiento alimentario garantizaban a los pequeños propietarios y a los colonos, en los años normales, una notable seguridad, muy superior a la que disfrutaba paralelamente las capas bajas urbanas. Su sistema de aprovisionamiento no estaba exento, sin embargo, de incovenientes, puesto que, en las épocas de carestía, abandonados a sí mismos y carentes de unas estructuras administrativas capaces de organizar las adquisiciones de cereales en áreas lejanas, el hambre les obligaba -como ya se ha expuesto- a acudir a las grandes ciudades en busca de sustento.

En las casas rurales, incluso en las más humildes, siempre hay, en los años normales, unas cuarteras de cereales, algunas piezas de carne salada y varios recipientes con vino. El autoabastecimiento cerealístico, en bastantes casos, constituiŕa, sin embargo, más un afán que una realidad, como se desprenden de la alta frecuencia con que aparecen, en la documentación notarial conservada, los préstamos en grano, modalidad de crédito rural que alcanzaba sus cotas máximas a principios de otoño, coincidiendo con la siembra, y, sobre todo, durante la primavera, en la época de la "soldadura". No son escasas las familias campesinas que, entre marzo y junio, para poder subsistir mientras llegan las mieses, se ven obligadas a solicitar, incluso en los años de meteorologfa favorable, algunas medidas de

\footnotetext{
${ }^{56}$ Como lo demuestran tanto el patrón de cultivo implantado en las pequeñas explotaciones, heterogéneo y estable, como el alto número de campesinos que llevan directamente sus cereales al molino.

57"Encore à la veille de la Révolution, en face d'une norriture bourgeoise ou mềne artisane déjà sensiblement évoluće, l'ordinaire du paysan restait singulièrement archaïque" (Les aliments de l'ancienne France, en J.J. Hémardinguer, ed., "Pour une histoire de l'alimentation", Paris, Armand Colin, p. 231).
} 
cereales a los miembros más solventes de la propia comunidad de aldea o a los señores.

El alimento básico, para todos los labradores, era el pan, que habra adquirido, también en el campo, una marcada simbología religiosa; tanto los pequeños propietarios como los colonos acostumbraban a consignar en su testamento una cantidad de pan para los pobres: Joan Armentera, de Santa Maria de Corco (Osona), lega, en 1441, una cuartera de trigo ${ }^{58}$; los indigentes que acudan a su funeral recibirán, pues, un pan blanco, ur. manjar poco menos que exquisito para una amplia franja de la población rural, puesto que, por esta época, sólo lo consume en los banquetes o cuando efectúa determinadas prestaciones laborales en la reserva de algunos señoríos $^{59}$. Las mujeres masoveras, al disponer normalmente, como ponen de manifiesto los inventarios, de artesa y horno propios, no necesitarían, para preparar la hogaza, ninguna colaboración externa, difícil de obtener en una explotación aislada. En las aldeas, bastantes familias amasaban el pan en casa y lo cocian, en cambio, en el horno público, que pertenecía al rey o al señor. Junto al molino, el horno se ha convertido, durante los siglos XII y XIII, en una importante fuente de rentas. El titular, durante la Baja Edad Media, no suele explotar directamente el horno, acostumbra a arrendarlo a un particular o a la propia comunidad, la cual lo conffa, a su vez, a uno o varios vecinos, quienes aseguran su funcionamiento.

El pan de los payeses acomodados, como los titulares del mas L'Avenc $^{60}$, en Tavertet (Osona), era de trigo; el de las familias normales de mezcla de cereales, de trigo y cebada ${ }^{61}$, de trigo y centeno ${ }^{62}$ o de cente-

\footnotetext{
${ }^{58}$ Arxiu Particular Ententes, doc. 36; cit A. SERRA, La comunitat rural a la Catalunya Medieval: Collsacabra (ss. XIII-XVI), Vic, Eumo ed., p. 227, nota 7.

${ }^{59}$ La familia Cruilles, desde 1407, of recian a sus payeses del dominio de Begur, en el Baix Empordà, una comarca rica en cereales, cuando acudían a la reserva a efectuar las jovas, las traginas y las guardias armadas, pan de trigo (J. PELl. Y Y FORGAS, Historia del Ampurdán. Estudio de la civilización en las comarcas del noreste de Cataluña, 2“ ed., Olot, Aubert, 1980, p. 649).

${ }^{60}$ En cuya cocina, habia, según un inventario del último cuarto del siglo $\mathrm{XV}$, veintiuna cuarteras de trigo y cuatro de harina del misıno cereal (Arxiu Episcopal de Vic, Protocols Notarials de Tavertet, R/16, fols. 40 v.-54 r.; cit. A. SERRA, La comunitat rural, p. 227).

${ }^{61}$ En el mas Noguer, de la misma coinarca, se siembran, por la misma época, cuatro octavos de cebada y uno de trigo (AEV, PNT, R/16, 66 v.-69 r.; cit. Ibidem).

${ }^{62}$ En la encomienda hospitalaria de Manosques, en Provenza, el administrador, a mediados del siglo XIV, asigna anualmente a cada trabajador del campo 20 sextarios de morcajo ( $L$. STOUFF, Ravitaillement et alimentation en Provence, p. 221).
} 
no y mijo ${ }^{63}$. En los hogares pobres se consumiría frecuentemente pan de cebada $^{64}$, de centeno ${ }^{65}$ y de espelta ${ }^{66}$. Un sector importante del campesinado reservaba el cereal "noble" para el mercado. La necesidad de disponer de unos recursos mínimos en metálico, para pagar los censos, las cargas fiscales y las compras de los pocos artículos manufacturados y alimentos que no eran capaces de producir, le obligaba a renunciar al trigo, cuyo cultivo prosperaba también en las pequeñas explotaciones. El color y textura de la hogaza, en las áreas rurales, dependran, pues, del grado de solvencia del destinatario.

El nivel de renta de los payeses se refleja también en la estructura de su dieta ordinaria, en la incidencia del pan en el presupuesto alimentario, que, entre los trabajadores de las encomiendas hospitalarias provenzales, oscila, hacia 1340, entre 55 y el $70 \%$. Los labriegos, a mediados del siglo XIV, consumen normalmente, pues, mucho pan de calidad media o baja y poco companage. La revalorización de la fuerza de trabajo provocada por la Peste Negra repercutirá favorablemente, sin embargo, en las condiciones de vida de las capas más representativas de la población rural, en cuyo sistema alimentario el pan retrocederá frente al companage y el

\footnotetext{
${ }^{63}$ Cereales que aparecen en la mayoría de explotaciones de Collsacabra inventariadas en los siglos XIV y XV (A. SERRA, La coinunitat rural, p. 227).

${ }^{6}$ En el último tercio del siglo XIV, cl pastor, en Cataluña, según F. Eiximenis, iba detrás de las ovejas, "menjant pa d'ordi ab aygua, e tart havia cuyna" (Terç del Crestià, cap. CCCCXXIX, p. 238; cit J.V. GARCIA MARSILLA, La jerarquia de la mesa, p. 160). Los campesinos italianos, excepto en las áreas más fértiles, también consumían normalmente, por esta misma época, pan de cebada (M. MONTANARI, Campagne medievali, p. 204). La familia Quinqueran, de Arles, en cambio, repartía, en 1402, pan de trigo entre sus pastores y reservaba el de cebada, la cannine, para los perros que custodian sus rebaños (L. STOUFF, Ravitaillement et alimentation en Provence, p. 47). Los Cruilles, por esta misma época, también proporcionaban a sus payeses del dominio de Begur, durante sus periódicas prestaciones laborales en la reserva, pan de trigo, excepto en los dos últimos días de las jovas y en las jomadas de traginas de estiércol, cuando les entregaban pan de cebada, alimento basto que parecen asociar a las tareas agrarias más sucias (J. PELLA Y FORGAS, Historia del Ampurdán, p. 649).

${ }^{65}$ En algunas de las encomiendas hospitalarias provenzales, los bubulci, los trabajadores de la reserva, reciben, a incdiados del siglo XIV, pan de centeno (L. STOUFF, Ravitaillement et alimentation en Provence, p. 44). Los señores ingleses, por esta misma época, también proporcionaban a sus siervos, durante las mieses, pan de centeno (H.S. BENNETT, Life on the English Manor: A Study of Peasans Conditions, 1150-1400, Cambridge, Cambridge University Press, 1937, pp, 235-236). Tanto en el continente como en las islas, se consideraba normal proporcionar a estos hombres nísticos, cuando ejecutaban tareas penosas, grandes raciones de pan de baja calidad. Los campesinos italianos de las áreas de montaña, durante la etapa final del medievo, continúan consumiendo pan de centeno (M. MONTANARI, Campagne medievali, p. 203).
}

${ }^{66} \mathrm{M}$. MONTANARI, Campagne medievali, p. 203. 
vino; en el dominio real de Gardanne (Bouches-du-Rhône), el manjar básico, en 1457, ya sólo significa el $45 \%$ del valor global de la dieta de los campesinos. Estos cálculos, efectuados por Louis Stouff ${ }^{67}$ a partir de las dietas ofrecidas, en Provenza, por dos poderosos señores, la Orden del Hospital y el rey Renato de Anjou, a sus respectivos payeses, cuando estos acudían a la reserva para realizar los servicios laborales, no pueden extrapolarse, sin las correspondientes comprobaciones documentales, al conjuto de los territorios del Mediterráneo noroccidental; fuera de los núcleos centrales de la gran propiedad de los valles del Ródano y el Durance, sólo tienen un valor indicativo. Es probable que el cambio alimentario, en los mansos coloniles y en las aldeas de pequeños alodieros, avanzase a un ritmo algo más lento. Las transformaciones experimentadas, en la etapa final de la Edad Media, por la economia y la sociedad rurales se tradujeron en una mejora cualitativa de la alimentación campesina, en una presencia más frecuente de la carne en las mesas de los payeses ${ }^{68}$, proceso que no se desarrollo sincrónicamente ni alcanzó las mismas cotas en las diversas regiones de Occidente.

Estas mutaciones económicas, sociales y alimentarias no erradicaron, sin embargo, las crisis de subsistencia, sólo las distanciaron en el tiempo. Cuando reaparecía el hambre y se agotaban las reservas de comestibles ordinarios, los labradores, para poder sobrevivir, se velan obligados, como en las peores épocas del pasado, a rebajar al máximo sus exigencias y a integrar en su dieta cotidiana el salvado, las raices de plantas silvestres, los helechos, la grama, las pepitas de uva, la corteza de árboles, las cáscaras de nuez o de almendra, el polvo de teja ${ }^{69}$ y otros alimentos inmundos, de dif́cil digestión y escaso contenido nutritivo. Durante las penurias, las fronteras alimenticias entre hombres y animales se atenuaban hasta desaparecer: el sorgo, por ejemplo, pasaba del comedero de los cerdos a la mesa de los campesinos, los cuales, finalizadas sus existencias, acudian, para atenuar su hambre, al salvado, disuelto en agua caliente ${ }^{70}$.

${ }^{67}$ Ravitaillement et alimentation en Provence, pp. 222-225.

${ }^{60}$ S. MENNELL, Français et anglais da table, p. 44.

${ }^{60}$ Productos con los que un amplio sector de la payesía de la región del Vivaroise atravesó la crisis de 1585-1586 (É. LE ROY LADURIE, Les Paysans du Languedoc, Paris, SEVPEN, 1966, I, p. 399).

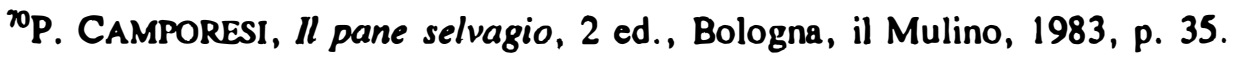


El miedo a morir de inanición, desigualmente repartido entre los diversos estamentos sociales, más fuerte en el campo que en la ciudad, constituye, según Robert Mandrou ${ }^{71}$, uno de rasgos más característicos de la Europa preindustrial. Los temas del hambre, del abandono de niños e incluso del canibalismo, tan comunes en el folklore occidental del bajo medievo y de la alta modernidad, reflejan también este temor, omnipresente, de carecer de comida. Los antiguos mitos inversos, de las comilonas y los banquetes, que, en el siglo XIII, dan origen, en Francia, a la fábula de la Cocaigne, y, en Inglaterra, al poema The Land of Cockaygne ${ }^{72}$, dimanan también de esta misma inquietud.

La cantidad de carne integrada en la dieta ordinaria variaba, como la del pan, en función de los recursos del titular, pudiendo llegar a ser, incluso después de la Peste Negra, muy escasa entre los estratos inferiores $^{\text {T3}}$; las variedades más consumidas eran la oveja, el cordero y la cabra, durante la primavera y el verano, el cerdo salado $^{74}$, en invierno, y la ga$1 l i n a$, en cualquier época del año ${ }^{75}$. En la Alta Edad Media, el cerdo, cria-

${ }^{71}$ Introduction à la France Moderne, 1500-1600, Paris, Albin Michel, 1961, pp. 26-27.

${ }^{72}$ S. MENNELL, Français et anglais da table, p. 47.

${ }^{73}$ "Le morceau de mouton qu'une fois par semaine on peut acquerir chez le fermier de la boucherie, l'agneau quelquefois tué pour Pâques, le porc salé que l'on a elevé et abattu à la maison et que l'on mange au cours des mois d'hiver, la pièce de boeuf que l'on achète à la Noël et, avec beaucoup de chance, en une o deux autres ocasions: voilà à quoi se réduit la consomation de viande dans les chaınpagnes. Elle est loin d'être una habitude quotidiene" (L. STOUFF, Ravitaillement et alimentation en Provence, p. 181). Entre amplios sectores de la payesía catalana, la situación no scría muy diferente a la descrita, para el campesinado provenzal, por el historiador francés. El alza del consumo de carne subsiguiente a la Peste Negra no debió de alcanzar, en los paises mediterráneos, la cotas propuestas, para las campiñas atlánticas, por G. Schmoller [Die historiche Entwicklung des Fleischkonsums sowie der Vieh-und Fleischpreise in Deuschiland, "Zeitschrift fur die gessamte Staatwissenchaft", XXVII (Tubingen, 1871), pp. 284-362], W. Abel [Wandlungen des Fleischverbrauchs und der Fleischversorgung in Deutschland seit dem ausgehenden Mittelalter, "Berichte über Landwirtschaft. Zeitschrift für Agrarpolitik und Landwirtschaft", XXII-3 (Berlin, 1937), pp. 411-452] y F. Braudel (Civilisation matérielle, éconoınie el capitalisıne, XV-XVIII siécles, Paris, Armand Colin, 1967, I, p. 163).

${ }^{74}$ En el comedor del mas l'Avenc, en las últimas décadas del siglo $\mathrm{XV}$, se guardaban cuatro bacons -piezas de tocino saladas- de 30 libras y cuatro espaldas (Véase supra, p. 873, nota 60 ).

${ }^{75}$ Los restos óseos aportados por las excavaciones del Bullidor de Sant Just Desvern ponen de manifiesto que "el consum més elevat en el jaciment és el de l'espècie ovicaprina, les restes de la qual són més de la meitat del total trobat. Això significa que l'economia càmia de la comunitat es basava primordialment en el consum de bestiar oví. En comparació, el bestiar boví té molt poca importància $\mathrm{i}$ una representació mitjana la donen al porc i la gallina" (J. AMIGó-J. BARBERA-J. CORTADELLA-D. GUASCH-J.M. SOLJAR-M.A. CORTÉs, El Bullidor, jaciment inedieval. Estudi de materials i documentaci6, Sant Just Desvern, 1987, pp. 63-72). 
do en estado bravío, en los amplios espacios boscosos de uso comunal, había desempeñado un papel importante en el sistema alimentario de los campesinos $^{76}$, al garantizar una aportación relevante y continua de salazones y embutidos a su dieta cotidiana. Durante los siglos centrales del Medievo, el retroceso de las masas forestales y la paulatina regulación de su acceso repercutieron negativamente sobre la ganadería porcina, el consumo de cuya carne experimentó, entre las capas bajas rurales, una fuerte carda. El reavance de los yermos subsiguiente a la Peste Negra no constituye tampoco un estímulo eficaz para este sector. Los campos abandonados por la contracción de la mano de obra rural no se transforman en bosques de encinas o robles, sino en praderas naturales, un tipo de paisaje más apto para los rumiantes que para los suidos. Mientras la ganadería ovina, que proporcionaba lana y leche, además de carne, experimenta, desde 1350, un crecimiento ininterrumpido, como se desprende del auge de la trashumancia en los países mediterráneos, la de cerda, al pasar de bravía a estabulada, acelera su ocaso. La caza, que había constituido, en el Alto Medievo, una actividad muy habitual entre los campesinos, también chocó, entre 1150 y 1350 , con las eficaces restricciones impuestas por los poderes locales a la libre explotación de las florestas. El despoblamiento rural y las concesiones efectuadas, para evitar la fuga de mano de obra, por los señores permiten de nuevo a los payeses, durante el tercer cuarto del siglo XIV, abastecerse de carne fresca, miel, frutos silvestres y setas en los bosques. La situación se revelará, sin embargo, como transitoria, puesto que los grandes terratenientes, superada la fase álgida de la crisis, restablecerán paulatinamente el control sobre sus yermos. Los conejos, las liebres, los gallos, las perdices y las becadas retroceden, a lo largo del siglo XV, en la dieta de los campesinos, sin llegar a desaparecer. El vacío generado por su caŕda será colmado por la oveja y la cabra, presentes en todas las explotaciones, incluso en las más pequeñas.

Si del Barcelonés pasamos a una comarca de montaña, al Pallars Jussà, el resultado es parecido (D. BUIXÓ, L'estudi de la fauna del jaciment de Sant Miquel de la Vall. Tesis de Licenciatura, Universidad de Barcelona, 1985, dactilografiada).

${ }^{76}$ M. Montanari-M. Barutzi, Porci e porcari nel Medioevo. Paesaggio, economia, alimentazione, Bologna, Cluch, 1981. A. RIIRA MEIJS, El sistema alimentario como elemento de diferenciación social en la Alta Edad Media. Occidente, siglos VIII-XII, "Representaciones de la sociedad en la historia: de la autocomplacencia a la utopía", Valladolid, Instituto de Historia Simancas, 1991, pp. 47-48. 
El queso, especialmente en las comarcas de montaña, se empleaba como substituto o complemento de la carne ${ }^{\eta}$. En unos países relativamente secos, donde, excepto en las áreas de pastos de altura y en las grandes reservas señoriales, las vacas se destinaban al tiro y no a la recría, eran las ovejas y las cabras las que garantizaban la mayor parte de la leche necesaria para elaborar los quesos. Raras serían las casas rurales, dada la frecuente presencia de este producto lácteo en los censos en especie ${ }^{78}$, que no dispusieran de los instrumentos indispensables para la caseificación. En algunos contratos de cesión de ganado, se estipula que el concesionario y el cedente de los animales se repartirán los quesos producidos con su leche.

Con legumbres y verduras, dos víveres fáciles de obtener en el campo, las mujeres payesas preparaban potajes y menestras ${ }^{79}$, dos platos bien conocidos en muchos hogares rurales ${ }^{80}$. Las habas, los guisantes, las lentejas, los garbanzos y las arvejas, cuyo cultivo arraigaba tanto en los regadíos como en los secanos, donde alternaban con el de los cereales ${ }^{81}$, aparecen citados a menudo en la documentación generada, en los siglos $\mathrm{XIV}$ y XV, por los labriegos mediterráneos. Las habas, que se comsumfan tanto frescas como secas, ocupaban un lugar destacado en la alimentación campesina y eclipsaban a las restantes legumbres. Las verduras, cultivadas casi exclusivamente en los pequeños huertos familiares, eran también nu-

\footnotetext{
${ }^{77}$ A RIERA MELus, Ganaderia, quesos y derivados de la leche en el Medieovo catalanoaragonés, "Il caseario. Un archetipo alimentare: il latte c le sue metamorfosi", Bologna, Consorzio Eıniliano Romagnolo produttori latte, 1885, pp. 50-57. Joan Armentera, en su testamento, consigna una cantidad de quesos para repartir entre los pobres que acudan al funeral (Véase supra, p. 873, nota 58).

${ }^{78}$ Figura en treinta y cinco de los que percibe anualmente, según el capbreu de 1379 , el señor de Rupit de sus sesenta y cinco payeses (E. SERRA, La coinunital rural, p. 75). Los colonos del dominio de Begur, desde 1407, entregaban anualmente a la familia Cruïlles, el día que acudían a la era scinorial para efectuar el servicio de trilla, un queso de los que se acostumbraban a elaborar en la comarca (J. PELLA Y FORGAS, Historia del Aimpurdán, p. 649).

${ }^{79}$ Veintiuno de los payeses de Rupit, según el capbreu de 1379, pagan, entre otras cosas, a su señor, en concepto de censo, una olla de coles cocidas (A. SERRA, La comunitat rural, pp. 73-74 y 228), componente censual que también tenemos documentado, por esta misma época, en la Vall d'Hostoles y el Gironès

${ }^{80}$ Tanto de Cataluña y Provenza (L. STOUF, Ravitaillement et alimentation en Provence, p. 233), como de Inglaterra (S. MENNEL. Français et anglais a table, du moyen age d nos jours, Paris, Flammarion, 1987, pp. 72-73).

${ }^{81}$ Los payeses de Rupit y Tavertct, en los siglos XIV y XV, estaban facultados, como se hace constar en los capbreus, para cultivar, en las sementeras de sus respectivos mansos, legumbres, cáñamo y nabos, además de mijo y otros cereales (A. SERRA, La coınunitat rural, p. 228).
} 
merosas, aunque no todas desempeñaban un papel idéntico en la dieta ordinaria de los payeses. La col, en alguna de sus tres variantes, verde, blanca o repollo, se consumía, en otoño e invierno, varias veces por semana. Los puerros y las espinacas, con una producción bastante más estrecha, aportaban un poco de variedad a los potajes durante las largos meses presididos por la col. La cebolla y el ajo constituyen, todavía hoy, dos condimentos básicos, indispensables, en las cocinas populares mediterráneas. Estas cinco hortalizas, que algunos naturalistas calificaban de alimentos vulgares, impropios de gente selecta ${ }^{82}$, entraban regularmente, crudas, hervidas, fritas o guisadas, en el companage de los labradores catalanes, occitanos y provenzales. La calabaza, el pepino, el nabo, el rábano, la acelga, la borraja, la lechuga y la verdolaga aparecían con bastante menos frecuencia en las mesas rurales. Las mujeres aldeanas sazonaban sus guisos con algunas plantas aromáticas, como el tomillo, la mejorana, la albahaca, el laurel, el hinojo o la salvia, de fácil recolección o cultivo en las soleadas y secas riberas mediterráneas. La fruta fresca, aunque su consumo experimentase un cierto crecimiento, no rebas $\sigma$, en la dieta ordinaria de amplios sectores del campesinado, el papel de componente secundario, de alimento de lujo, impropio de los estamentos populares.

La bebida ordinaria es, como en la ciudad, el vino local, cuya cualidad depende tanto de las características edáfico-climáticas de la comarca como del instrumental y la experiencia acumulados por la familia elaborante. Las dietas cotidianas previstas en las pensiones alimentarias y las raciones distribuidas por los agentes señoriales entre los trabajadores del campo, incluso las correspondientes a mujeres, comprenden siempre, además del pan y el companage, el vino. Los pequeños propietarios y los colonos, como los restantes estamentos sociales, no renuncian a la bebida espiritosa ni en las jornadas de mortificación; la dureza del trabajo y una dieta cotidiana escasa en carne pueden justificar, en este caso, la inclusión de un componente euforizante en unas comidas destinadas a disciplinar los instintos. El lugar central que los campesinos asignan al vino en su sistema

\footnotetext{
${ }^{82}$ Por desarrollarse bajo el suelo y crecer en estrecho contacto con la tierra. "El humor alimentario de la planta es más insipido en la raíz, y a medida que se aleja de la raiz va adquiriendo un sabor conveniente" (P. DE' CRESCENZI, Trattato della agricoltura, Bolonia, I, 1784, p. 50; cit. M. MONTANAKI, El hainbre y la abundancia, p. 92, nota 60).
} 
alimentario explica que cada explotación disponga de viñas y de bodega ${ }^{83}$. Las familias rurales sólo acuden al mercado en busca de vino cuando han agotado el propio, de sus viñas esperan la autosuficiencia en caldos y, subsidiariamente, excedentes para comercial izar.

En los días de abstinencia, la dieta giraba en torno al queso, los huevos o el pescado, que sólo se consumía fresco en las inmediaciones de las numerosas pesqueras fluviales y en el litoral. Las especies más asequibles, en las regiones interiores, eran la trucha, el lucio, el barbo y la tenca. Los payeses de las franjas costeras cumplirían, en cambio, algunas de las frecuentes restricciones alimentarias con sardinas, arenques y congrio, alimentos que, a diferencia del queso o los huevos, adquiririan en los mercados locales o directamente de los pescadores. La salazón y el ahumado, dos operaciones que bastantes familias rurales practicaban con asiduidad, permitran escalonar el consumo del pescado, una de las viandas más perecederas, a lo largo del año. Durante la estación cálida, por razones sanitarias, las conservas desplazaban casi integramente, en las mesas campesinas, al pescado fresco

Las jornadas festivas, bastante menos frecuentes que las penitenciales, se celebraban, en los hogares campesinos, con una comida extraordinaria, cuya composición podemos intuir a través de los almuerzos que los colonos ofrecían periódicamente a sus señores y de los banquetes colectivos rurales. Los payeses, cada año, renovaban simbólicamente la fidelidad y la sumisión a su señor, "invitándole" a un ágape, que, en la zona de Collsacabra (Osona), constaba normalmente de pan, vino y carne asada o guisada con coles $^{84}$. Las comidas comunitarias, en el campo, solian ser convocadas por los concejos o las cofradías, con motivos diversos, tales como la finalización de algún servicio laboral colectivo, la admisión de un nuevo miembro o la celebración de una sesión extraordinaria. En Castilla la Vieja, a principios del siglo XVI, los participantes en estos banquetes rurales reciben un potaje de legumbres, verduras, tocino salado y harina, un plato principal de carne asada, normalmente de carnero o de volatería, pan blanco, vino, frutos secos y miel, en la estación fría, o fruta del tiempo, duran-

\footnotetext{
${ }^{83}$ Las cuales, incluso las más pequeñas, disponen, como demuestran los inventarios notariales, de lagar, embudos, toneles o botas y barriles (E. SERRA, El vi, la seva importància i la seva elaboració entre els s. XIII-XVI a la Catalunya central, "Vinyes i vins: mil anys d'història", Barcelona, Publicacions de la Universitat de Barcelona, II, 1993, pp. 294-296).
}

${ }^{84}$ A. SERRA, La comunitat rural, p. 231. 
te la primavera y el verano ${ }^{85}$. Los menús de fiesta -el máximo gastronómico a que podía aspirar el sector más representativo del campesinado- no experimentarían, en una época en que el sistema alimentario de una persona dependía más -como ya se ha expuesto- del estamento social a que pertenecía que de la lengua que hablaba, cambios importantes al pasar del valle del Duero a Cataluña y a los restantes países del Mediterráneo noroccidental. Debería de ser durante estas jornadas alegres cuando aparecerian en las mesas campesinas las placentulas, tortas de harina de trigo, queso tierno y miel $^{86}$, uno de los pocos dulces rurales documentados en la Catalunya bajomedival

\section{CONCLUSIONES}

Entre 1110 y 1280 , un conjunto de fenómenos heterogéneos pero convergentes, como el alza de la población, el avance de los frentes roturadores a expensas de los yermos, la instauración del orden feudal en el campo, la reactivación de los intercambios mercantiles, el despertar de las ciudades, la difusión del uso de la moneda y del crédito, y el triunfo de una mentalidad económica más dinàmica, habra dejado sentir sus efectos sobre amplios sectores de la población europea, modificando sus respectivos sistemas alimentarios. La dieta ordinaria de los estratos sociales inferiores ha perdido, durante estos ciento ochenta años, la diversidad que la caracterizó durante la Alta Edad Media; los cereales han eclipsado las restantes viandas, relegándolas, como en la época romana, a la condición de companage.

La capacidad de crecimiento de las sociedades feudales, que no era ilimitada, toca techo a finales del siglo XIII. El equilibrio, siempre precario, entre población y recursos se quiebra y reaparece el hambre. Este cambio de tendencia no es imputable sólo a un dispar comportamiento de la

\footnotetext{
${ }^{85} \mathrm{H}$. CASADO, Le banquet de l'assemble communale rurale en Vieille Castille "La sociabilité à table. Commensalité et convivialité à travers les âges", Rouen, Publicacions de l'Université, 1992, pp. 203-205.

${ }^{86}$ Parecidas a las que la faınilia Cruïlles, desde 1407, of recía a sus payeses del dominio de Begur, cuando acudian, durante el invierno, a entregarle el cuarto de cerdo a que estaban obligados (J. PEL.LA Y FORGAS, Historia del Ainpurdán, pp. 648-649).
} 
demografía y de la oferta global de alimentos, obedece también a muchas otras causas, de nautaleza diversa.

El trigo y los demás cereales panificables provienen de los campos de cultivo permenente. La capacidad de reacción de la agricultura mediterránea frente a los nuevos tiempos, como consecuencia de una tecnología débil y unas estructuras rígidas, es bastante limitada. La fragilidad crónica de los rendimientos, más que las oscilaciones climáticas, provoca periodicamente problemas de abastecimiento. Las penurias de grano, escasas durante la etapa central de la Edad Media, se repiten, desde principios del siglo XIV, con frecuencia, provocando periódicas situaciones de emergencia.

La expansión de las ciudades y los cambios en la dieta de amplios sectores de la población urbana, al romper paulatinamente los antiguos equilibrios regionales, acentúan, desde 1300 , la dependencia del mercado local de alimentos del comercio internacional. Los concejos de las grandes urbes, conscientes de esta dependencia exterior, improvisan una serie de medidas tendentes a estimular la afluencia de cereales, a contener los peligrosos efectos de las bruscas caídas de la oferta interior. Los hombres de negocios, hasta principios del siglo XIV, hablan puesto en circulación preferentemente artículos de lujo, de alto valor y escaso peso, destinados a los estamentos privilegiados, y algunos alimentos imprescindibles, como la sal, el trigo y el vino. La acentuación de la divisón social del trabajo, el incremento de la productividad de los medios de transporte, especialmente de los marítimos, y la difusión de unas técnicas mercantiles, contables y financieras más decididamente capitalistas permiten, desde el segundo tercio de la centuria, que los artículos pobres y los comestibles no vitales efectuen desplazamientos cada vez más largos. Esta reducción progresiva de la incidencia de los costos de transporte en el precio de los alimentos ordinarios permite una cierta especialización regional y amplía considerablemente el sector de consumidores que dependen, para su abastecimiento cotidiano, del mercado. La aristocracia y el patriciado urbano, con un poder adquisitivo elevado, con una gran capacidad de resistencia frente a las oscilaciones de precios, serán los grandes beneficiarios de esta ampliación de la oferta mercantil de alimentos, que les permitirá diversificar aún más su ya larga dieta ordinaria.

Las dificultades económicas y los cambios estructurales actúan sobre el conjunto social de forma selectiva, acentuando su jerarquización interna, incrementando las diferencias que separaban las dietas cotidianas de los grupos poderosos de las de los estamentos populares. 
Entre el sistema alimentario de los menestrales y el de los campesinos las coincidencias preponderan claramante sobre las discrepancias. Ambos giran en torno al pan, cuya incidencia en el valor global de la dieta pasa, entre 1300 y 1450 , del 65 al $45 \%$ aproximadamente. El vino y los potajes de legumbres y venduras integran el companage ordinario. La presencia de la carne fresca, muy escasa durante la primera mitad del siglo XIV, se incrementa ligeramente después de la Peste Negra. Un trozo pequeño de cabra, oveja o cerda, tres animales de escaso valor, alegra, a finales del Medioevo, dos o tres veces por semana, las mesas de los estamentos subalternos rurales y urbanos. El queso, el pescado salado o los huevos acompañan, en los días penitenciales, al pedazo de pan y al jarro de vino. La fruta, el pescado fresco y las carnes finas (el carnero y la volatería) ocupan un lugar periférico en la dieta del poble menut, para el que constituyen alimentos superfluos o de lujo, cuyo consumo continúa circunscrito a los banquetes. La agricultura, que el triunfo del Feudalismo habia convertido en la principal fuente de alimentos, conservo su protagonismo durante la primera mitad del siglo XIV. El avance de los pastos y el auge de la ganadería permiten a las capas bajas rurales y urbanas, depués del crac demográfico de 1348, diversificar su régimen ordinario e incrementar el consumo de queso y carne, dos viandas que, sin embargo, no conseguirán desplazar al pan, el vino y las legumbres del centro del sistema alimentario. En las mesas populares del Mediterráneo noroccidental, los manjares de origen vegetal continúan eclipsando, a fines del Medievo, los de procedencia animal.

Ciudad y campo constituran, desde 1200, dos ámbitos económicos complementarios, es lógico, pues, que las cocinas de sus respectivos estamentos subalternos, en la última fase de la Edad Media, no coincidan plenamente. Mientras que amplios sectores del campesinado no desdeñan la hogaza de mezcla de cereales, los menestrales, en los años normales, consumen pan integral de trigo. La composición de los potajes y las menestras rurales es algo más diversificada que la de los urbanos; a la ciudad sólo llegan las verduras, las legumbres y los condimientos de cierta calidad, los costes de transporte impiden la circulación extracomarcal de las variedades más bastas. La caza continúa desempeñando, a pesar del retroceso experimentado desde el siglo XII, como consecuencia de las restricciones impuestas por los poderes locales a la libre explotación de los bosques, un papel más importante en el sistema alimentario de los payeses que en el de los artesanos. Las diferencias principales que separan ambas cocinas dimanan 
de los mecanismos de aprovisionamiento: los campesinos, en contacto directo con las sementeras y los yermos, producen la mayor parte de los alimentos que consumen y acuden al mercado más a vender artículos de calidad que a adquirir viandas ordinarias; los estamentos bajos urbanos, al no disponer de cosecha propia, compran la casi totalidad de los componentes de sus comidas cotidianas en la plaza. Los problemas alimentarios, en los años normales, son inferiores en el mundo rural que en el urbano; la situación cambia, sin embargo, durante las crisis de subsistencia, cuando los labradores, desprovistos de instituciones administrativas capaces de atraer trigo desde áreas lejanas, tienen que acudir, en busca de viveres, a las grandes ciudades, abastecidas con grano extranjero por los mercaderes y el concejo. La estrecha vinculación al mercado permite a los menestrales, a medida que las viandas pobres no imprescindibles se incorporan a los circuitos del comercio internacional, renovar paulatinamente su prácticas culinarias. Los plantamientos autárquicos confieren, por el contrario, una notable rigidez a la dieta de los campesinos. El cambio alimentario, a nivel de estamentos sociales subalternos, avanza, pues, bastante más deprisa en los núcleos urbanos que en las áreas rurales.

\section{RÉSUMÉ}

Comme conséquence de l'expansion économique et de l'établissement du système féodal, l'Occident a éprouvé, pendant la période centrale du Moyen Age, toute une série de changements alimentaires. Le pain devint, donc, l'aliment primordial pour les couches les plus basses de la société.

Étant donné que la croissance des sociétés féodales avait atteint son plus haut point vers la fin du XIII' siecle, l'équilibre -toujours précaireentre la population et les ressources s'est finalement rompu et la faim apparaît de nouveau.

La ville et la campagne étaient, dépuis 1200 , deux domaines économiques complémentaires, mais les cuisines de leurs subalternes respectifs n'étaient tout à fait égales vers la fin du Moyen Age. Or, les différences principales étaient une conséquence des mécanismes d'approvisionnement: ainsi les campagnards produisaient la plupart de leurs invariables nourritu- 
res, tandis que les classes inférieures urbanes dépendaient du marché dans lequel le changement alimentaire fut donc plus rapide.

\section{SUMMARY}

As a consequence both of economic expansion and the establishment of the feudal system, the West had to undergo some important changes in nourishment. Bread became the main element in the diet of the lower classes.

When the growth of feudal society had already achieved its highest point towards the end of the XIIIth Century, the ever precarious balance between the population and resources was broken and starvation appeared.

From about 1200 , town and country were two economically complementary areas, though the cooking of their respective subordinates was not the same towards the end of the Middle Ages. The main differences arose from mechanisms of supply: while country people produced most of their invariable food, the lower classes in the towns had to depend on the market and so their eating habits changed more rapidly. 